\title{
Trabajando PARA EL PUEBLO DE DIOS: \\ PALABRA, LEY Y CLERO EN EL PENSAMIENTO \\ DE ISIDORO DE SEVILLA (600-636)
}

\author{
Eleonora Dell' Elicine* \\ gardell@arnet.com.ar \\ eelicine@ungs.edu.ar
}

RESUMEN: ¿Qué relación puede haber entre un buen gobierno y un programa lingüístico? ¿En qué medida puede contribuir una reflexión sobre la lengua a la conducción de la res publica? De acuerdo a Isidoro, obispo de Sevilla y doctor prominente del reino visigodo de Toledo, la fijación de una lengua correcta y ortodoxa constituye el vector fundamental para orientar al pueblo a la salvación, en tanto que ayuda a los hombres a encontrar para los significantes que disponen aquel significado conveniente a los ojos de Dios. Alrededor del programa lingüístico, Isidoro monta una eclesiología y un plan de gobierno cristiano.

Palabras Clave: Isidoro de Sevilla, Programa lingüístico, Eclesiología.

En sus famosas Sentencias, redactadas probablemente en 633, Isidoro de Sevilla afirmaba lo siguiente:

A la culminación de algún hecho llamamos perfección, pero ¿cómo es perfecto Dios, que no ha sido hecho? Es que la incapacidad humana adoptó este lenguaje, como las demás expresiones, de conformidad con nuestro uso, para que pueda decirse de algún modo lo que es inefable, toda vez que el lenguaje humano nada puede afirmar de Dios con propiedad. (De Deo nihil digne humanus sermo dicit. ${ }^{1}$

De Deo nihil digne humanus sermo dicit... El lenguaje humano no puede decir lo inefable, no puede decir a Dios. ${ }^{2}$ Con su cuerpo de palabra,

* Doctora en Historia. Docente e investigadora en el Instituto de Historia Antigua y Medieval "J. L. Romero", Universidad de Buenos Aires y en el Instituto de Ciencias, Universidad Nacional de General Sarmiento. 
tampoco resulta capaz de agotar la Creación: dependiendo de a qué categoría gramatical pertenezca, la palabra sólo alcanza a ser indicio, imagen de otra cosa, etc. ${ }^{3} \mathrm{Y}$, para seguir sumando escollos, la palabra según el obispo sevillano puede ser origen del pecado ${ }^{4}$ y vehiculizar la mentira ${ }^{5}$.

Estaríamos desorientados, no obstante, si a partir de estas premisas rápidas dedujéramos que Isidoro consideraba al lenguaje un instrumento pernicioso para las criaturas humanas. El último padre de la iglesia no olvida que con palabras fue dada la revelación a los hombres en las Sagradas Escrituras, ${ }^{6}$ y que a través de una lengua se dirigen los hombres a Dios en el momento de la oración y del culto. ${ }^{7}$ Para Isidoro en suma, la lengua constituye la marca manifiesta de la inferioridad de los hombres, una marca que al activarse les señala que son objeto de creación y no Sujeto de la misma. ${ }^{8}$

Es por eso que, a diferencia de otros programas radicales de su tiempo, Isidoro no se aviene a limitar el ejercicio del discurso entre un grupo selecto de iniciados ${ }^{9}$ o a imponer normas rígidas a la emisión de la palabra. ${ }^{10}$ Sin renunciar a este expediente ${ }^{11}$ y siguiendo en este punto a Agustín, el doctor de Sevilla despliega alrededor del lenguaje una labor más positiva, general y amplia que las reglas monásticas que conocemos. Más positiva, porque el camino que intenta es explotar las posibilidades del discurso humano y no estancarse en sus limitaciones. Más general dado que, en esta tarea, busca precisar los usos correctos de las palabras, es decir, empleos que se ajusten a la naturaleza de lo que se pretende nombrar. Más amplia porque, de fructificar su empresa, aprovecharía a la iglesia toda, alcanzaría al conjunto grande de los fieles, criaturas vulnerables que no pueden renunciar a hablar. La labor que Isidoro desarrolla alrededor del lenguaje, en suma, compromete al tiempo una visión de la Iglesia y un trabajo pastoral. ${ }^{12}$

En este artículo intentaremos explorar dos de los expedientes a través de los cuales el obispo de Sevilla lleva a cabo esta empresa: el método etimológico y la regla canónica. No agotan ellos los recursos y resortes desplegados por Isidoro en su tarea: este examen debería comprender la formación de la biblioteca, de las colecciones canónicas, el trabajo exegético, la labor litúrgica, la formación de discípulos, la regulación de la actividad monástica, etc. y excedería grandemente el espacio que contamos. Lo puntual de la elección permite, sin embargo, advertir sin mediaciones la complejidad del programa isidoriano, retener la heterogeneidad de sus modos de intervención y por último avistar cuáles son las funciones que Isidoro prevee para el orden sacerdotal, en otros términos, cuál es la imagen y el plan que guarda para la iglesia. 


\section{Los aVATARES DEL DISCURSO HUMANO}

Ningún punto de partida mejor para abordar el problema que suscita el lenguaje para Isidoro que remitirse a la propia historia del discurso humano que él mismo sintetizó.

Siguiendo al Génesis, para el obispo de Sevilla la expresión humana está íntimamente atravesada por la historia de la Creación y los avatares del pecado. Antes de modelar al Hombre, en efecto, Dios habló; ${ }^{13}$ pero esta emisión primigenia guarda de acuerdo a Isidoro tres diferencias sustanciales respecto al lenguaje humano: en primer lugar, es una palabra poiética por excelencia, en segundo lugar no requirió testigo ni receptor alguno y para terminar no resulta fácilmente discernible la forma lingüística en la cual ese mensaje se expidió. ${ }^{14} \mathrm{El}$ carácter poiético justamente desliga a la palabra de cualquier adecuación a otra realidad previa: ese Fiat lux que la divinidad pronuncia abre la posibilidad para que las cosas cobren forma y emerjan.

El lenguaje del primer hombre ya no reviste esta capacidad creativa: la palabra de Adán en efecto no crea absolutamente nada, se atiene a designar lo que encuentra ya formado. Sin embargo, Isidoro recalca que los nombres otorgados por Adán a las cosas se ajustan puntillosamente a la naturaleza de lo que nombran; ${ }^{15}$ muy lejos de resultar caprichosos, evocan la esencia de lo creado. A su turno, la unidad del código también refuerza este realismo primigenio de la lengua humana: en efecto, de acuerdo a Isidoro, Adán y sus primeros descendientes hablan todos en una lengua originaria y única, la lengua hebrea. ${ }^{16}$

Para el obispo de Sevilla, el vínculo que mantenía unido a la palabra con la cosa creada se pierde definitivamente ya sea después del diluvio - de acuerdo a algunos pasajes - o luego de la construcción de la torre de Babel - si tomamos en cuenta a otros. ${ }^{17}$ En cualesquiera de las dos versiones, lo que resulta evidente es que en un momento dado las lenguas se multiplican y con ello se termina por disolver la garantía que mantenía vinculada a la palabra con la cosa creada: a partir de entonces, la lengua se despoja de sus reaseguros de verdad y queda librada al control de los humanos. ${ }^{18}$ Conforme avanzan los tiempos, la situación se torna aún más inquietante: en efecto, lo que Isidoro releva a su alrededor es la práctica de una lengua latina que califica como mixta, en tanto corrupta y envejecida, salpicada de barbarismos. ${ }^{19}$

Como podemos advertir, el proceso que traza Isidoro es la historia de un alejamiento, de un extrañamiento cada vez mayor entre el orden de 
las palabras y el orden de las cosas. Esto supone un doble peligro: por un lado, los hombres no alcanzan a comprender la creación montada por Dios para ellos, el sentido último de lo que los rodea. Por otra parte, las palabras desencajadas de sus referentes naturales pueden llevar a la perdición, al desvío del camino salvífico. Es por eso que, Isidoro, obispo de Sevilla, amigo de reyes y doctor de la iglesia se mete a gramático. ${ }^{20} \mathrm{En}$ la búsqueda del empleo correcto de las palabras, se accede al conocimiento de las cosas por Dios montadas y, a través de ello, a la inteligencia de los planes divinos para con los hombres.

\section{PASIÓN POR LO UNO}

Para llevar a cabo esta labor, Isidoro no va a tientas: por el contrario se mune de un método, el etimológico. En el siglo VII, el procedimiento es todo menos nuevo: en efecto, se remonta a Platón ${ }^{21}$ mas fueron los estoicos quienes explotaron con mayor finura este expediente. ${ }^{22}$ Tampoco es el único procedimiento que esgrime Isidoro, mas sí el principal. ${ }^{23}$

El método etimológico indaga el origen de la palabra con un doble fin: conocer su sentido correcto y acceder al conocimiento de la cosa. ${ }^{24}$ Incapaz de reparar la fisura abierta entre lenguaje y Creación en el plano de los hechos, este procedimiento sí puede, con todos los límites de la empresa humana, acercarse a la verdad en el plano del conocimiento: la etimología responde a una gnoseología. ${ }^{25}$

Observémoslo en acto: para ello, el libro XV de las Etimologías que trata de un tema banal como los edificios y los campos nos puede servir como ejemplo puntual. ${ }^{26}$ De forma sumaria, se pueden relevar allí por lo menos siete modos diferentes de remisión a los orígenes de una palabra: por procedencia de lenguas más antiguas - preferentemente el griego ${ }^{27}$ por derivación de otras palabras; ${ }^{28}$ por homofonía; ${ }^{29}$ por descomposición de la palabra; ${ }^{30}$ por la función que cumple la cosa; ${ }^{31}$ por la percepción de los sentidos $^{32} \mathrm{y}$ finalmente por el personaje que la ha instituido o fundado. ${ }^{33}$

Ante todo, y como podemos advertir, lejos de ser un camino lineal la etimología en Isidoro constituye un método que registra una multitud de procedimientos diferentes entre sí. Los agrupan, sin embargo, varias cuestiones comunes. Observemos primeramente que se trata de procedimientos formales orientados a identificar el origen del vocablo: esta objetividad del método sustrae inmediatamente la cuestión del libre flujo de las opiniones subjetivas. No se trata de acercamientos propio de curiosos, sino de indagación de expertos, que encuentran en el primer sentido de la 
palabra un índice para conocer la naturaleza verdadera de la cosa. Si bien el lenguaje es patrimonio de todos los seres humanos, su sentido último se instituye como competencia de unos pocos, que lo entienden y enseñan a todos los demás. ${ }^{34}$

Esta distancia que impone el método se refuerza con una segunda propiedad suya. Como mera figura retórica la etimología eventualmente puede emplearse en un discurso oral, pero del modo amplificado como la usa Isidoro, de hecho se convierte en un procedimiento que demanda escritura. ${ }^{35}$ La casualidad no es lo que otorga el conocimiento del sentido correcto de las palabras, antes bien los que acceden a él es porque saben leer, han recibido ese saber afanándose laboriosamente en los pliegues y repliegues de un texto ${ }^{36}$. Esta segunda propiedad, como podemos advertir, sólo puede contribuir a que la elite de los expertos se consolide y legitime. ${ }^{37}$

La tercera propiedad se desprende de las anteriores. No todas las palabras reconocen limpiamente un origen único: hay varios casos en donde la duda y la incerteza subsiste. En estas circunstancias, la escritura fija una o varias procedencias y acota la duda, decreta soluciones. ${ }^{38}$ Hay un texto primario- las Etymologias, justamente- que viene a asentar la ortodoxia y a despejar las incógnitas. ${ }^{39}$

Resumamos lo visto entonces: se recorta un grupo exclusivo, disciplinado en técnicas y competencias específicas, que abreva en una fuente literaria común. El obispo de Sevilla trata de definir para el grupo de los clérigos una función distintiva y singular, que es hacer entendible al conjunto de los hombres el proyecto pensado para ellos por Dios. ${ }^{40}$ De este modo, la labor sobre la materia lingüística adquiere una doble dimensión, pastoral y sacramental: pastoral en tanto difunde un mensaje en el interior de la comunidad de los hombres con fines salvíficos; sacramental en tanto demarca un grupo particularmente entrenado que hace de esa tarea su profesión. ${ }^{41}$ Una generación posterior a la conversión de los godos desde el arrianismo, en suma, este montaje que Isidoro realiza alrededor de la lengua entraña un auténtico programa eclesiológico. ${ }^{42}$

\section{LA NORMA JURÍDICA}

Ahora bien ¿qué clase de eclesiología es? ¿De qué visión de Iglesia se trata? Debemos ante todo intentar distinguir esta eclesiología singular de la matriz centralista, monárquica y jurídica que Gregorio VII instalará cuatro siglos después, y que aún hoy domina nuestros modos de acercamiento a la cuestión eclesiástica. ${ }^{43}$ 
Isidoro identifica a la Iglesia en primer lugar con la comunidad de fieles que habitan un territorio común- en este caso Hispania-, y que han sido confiados por Dios a un mismo rey - el rex visigothorum. Su trabajo sobre la lengua tiene justamente por función hacer circular el sentido correcto de las palabras, para que al menos esta feligresía encuentre el camino salvífico y eleve una ofrenda a Dios lo más digna posible.

En 619, Isidoro va a organizar una nueva intervención apelando esta vez al dispostivo jurídico. ${ }^{44}$ Como observa Rachel Stocking (2003, p.120) con certeza, en el concilio segundo de Sevilla Isidoro busca tomar distancia de las políticas centralizadoras del rey Sisebuto (612- 621). ${ }^{45}$ Lo que interesa relevar aquí es que, ya bien adelantado el proyecto literario del obispo, ${ }^{46} \mathrm{el}$ mecanismo elegido es la vía jurídica, es decir, impartir normas que organicen al sujeto encargado de llevar adelante la tarea sacramental y pastoral.

El expediente jurídico presenta en la situación tres ventajas importantes: en primer lugar munirse de la legitimidad y prestigio de las figuras del derecho romano; en segundo lugar comunicar una autoridad de manera clara y entendible para todos y, en tercer lugar, reforzar la verticalidad del poder en el interior de la iglesia.

De los trece artículos que componen el concilio, ocho tienen un contenido estrictamente disciplinar, otros dos dirimen disputas jurisdiccionales, dos se expiden acerca de cuestiones doctrinales y uno finalmente ordena cuestiones materiales. Como podemos claramente apreciar, los cánones se orientan a consolidar en su interior el grupo de los clérigos. El obispo de Sevilla emplea a la norma jurídica para transformar un conjunto social de límites todavía fluidos en una clasificación interna a la sociedad definida objetivamente de acuerdo a parámetros legales. A la manera de los senadores o decuriones, el proyecto de Isidoro es convertir al conglomerado heterogéneo de los consagrados a la vida religiosa en un ordo compacto y profesionalizado, dedicado en tiempo completo a la tarea de descifrar la Creación, comunicar su saber de acuerdo a las necesidades y ofrecer a Dios un contradón litúrgico decoroso.

En su carácter específicamente provincial, esta iniciativa conoce su límite, en tanto resulta incapaz de imponerse como tal al clero de las demás diócesis. Pero también allí mismo descansa su potencial, dado que, contraviniendo en escasa medida a las relaciones de fuerza de cada localidad, ofrece un modelo concreto de acción, se yergue como una referencia.

Catorce años después de Sevilla II, Isidoro motoriza un nuevo concilio. A juzgar por los resultados, el expediente de la referencia ha tenido efectos escasos, e Isidoro se vuelca de lleno a un modelo centralista apoyado 
en el Estado. Este modelo impone por medios jurídicos un idéntico esquema disciplinar, sacramental y de sustento material válido para todo el ámbito del reino.

Lugar relevante en la agenda del concilio ocupa el programa educativo dirigido al clero: en efecto, sus cánones preveen un esquema formativo, ${ }^{47}$ grados diferenciados de acceso a las sagradas escrituras y conocimiento de la doctrina cristiana ${ }^{48}$ y el empleo ortodoxo de ciertos libros. ${ }^{49}$ Este programa converge directamente con medidas que tienden a reforzar la disciplina del clero ${ }^{50}$ y a homogeneizar la liturgia. ${ }^{51}$ A través de este expediente, Isidoro completa la estructuración del clero visigodo a la manera de un ordo: grupo articulado y homogeneizado, interior al cuerpo social con funciones y privilegios regulados desde el derecho. Así constituido, el ordo clericorum va a ser el encargado de dirimir el sentido prístino de las palabras, su adecuación a las cosas y los modos más convenientes de ofrecerse a Dios. ${ }^{52} \mathrm{El}$ remedio propuesto por Isidoro para desambiguar el lenguaje humano es, en suma, un método formal y un sujeto instituido capaz de llevarlo a la práctica y difundir sus resultados.

\section{Conclusiones finales}

A lo largo de este trabajo, hemos visto cómo método y norma constituyen para el más célebre doctor de la iglesia visigoda dos expedientes fundamentales para articular un programa a la vez eclesiológico y social. La desambiguación del lenguaje constituye uno de los fundamentos en que se apoya el gobierno cristiano, preocupación máxima que desarrolla Isidoro en el póstumo de sus libros, con el cual nosotros abrimos esta ponencia: sus célebres Sententiae.

WORKING FOR THE PEOPLE OF GOD: WORD, LAW AND CLERGY IN THINKING ISIDORE of SeVIlHe (600-636)

АвsтRAст: What relation can exist between a good government and a linguistic program? To what extent can a reflection on the language contribute to the driving of the Res Publica? According to Isidoro, bishop of Seville and prominent doctor of the Visigothic kingdom of Toledo, the fixing of a correct and orthodox language constitutes the fundamental vector to orientate the people to salvation, whereas it helps men to find for the signifiers they possess the most convinient meaning to the eyes of God. Around a linguistic program, Isidoro mounts an ecclesiology and a plan of Christian government.

KEY wORDS: Isidoro of Seville, Lingüistic program, Ecclesiology. 
NOTAS

1 "De consummatione alicuius facti dicitur perfectio. Deus autem qui non est factus quomodo est perfectus? Sed hunc sermonem de uso nostro sumit humana inopia, sicut et reliqua verba, quatenus id quod ineffabile est utcumque dici possit, quoniam de Deo nihil digne humanus sermo dicit”. Isid. Hisp, Sent. I, 2, 4, ed. CAZIER, P. (1998). En este, como en otros tantos puntos, Isidoro retoma una rica tradición de profundo arraigo en la península. Martín de Braga (510?-579?), para el caso del reino suevo, escribe por ejemplo: "Epistolam tuae sanctae caritatis accepi, in qua scribis ad me ut pro castigatione rusticorum, qui adhuc pristina paganorum superstitione detenti cultum venerationis plus daemoniis quam deo persolvunt, aliqua de origine idolorum et sceleribus ipsorum vel pauca de multis ad te scripta dirigerem. Sed quia oportet ab initio mundi vel modicam illis rationis notitiam quasi pro gustu porrigere, necesse me fuit ingentem praeteritorum temporum gestorumque silvam breviato tenuis compendii sermone contingere et cibum rusticis rustico sermone condire". Mart. Bracc., De correctione rusticorum 1, 1-2. ed. NALDINI, M. (1991). En la Galia, Cesáreo de Arlés sigue la misma línea de razonamiento: "Sicut enim optime nostris, duo sunt eleemosinarum genera: unum est, ut esurienti porrigatur buccella; aliud, ut ignoranti subministretur doctrina. (..) Elemosinam animae, id est cibum doctrinae maxime sacerdotibus convenit erogare (..)". Caes.Arel., Sermo 1,8; ed. DELAGE, M. (1971).

2 En Etym. VII, 1, 1- 18, Isidoro pasa revista a los diez nombres básicos que Dios recibe en la tradición hebrea reseñados a su vez por san Jerónimo. Alude cada uno de ellos a una propiedad particular de Dios; de modo individual jamás llegan a cubrir su esencia. La enumeración tampoco lo hace, y luego de los diez nombres Isidoro continúa enumerando nombres menos frecuentes que remiten a otras tantas propiedades divinas. Ver para ello OROZ RETA, J., San Isidoro de Sevilla, Etimologías, BAC 432, Madrid, 1982.

3 En las Etimologías, define las palabras de este modo: "Sunt autem verba mentis signa, quibus homines cogitationes suas invicem loquendo demostrant.Sicut autem nomen significat personam, ita verbum factum dictumque personae". Isid., Etym I, 9, 1 ed. OROZ RETA, J; MARCOS CASQUERO, M. (1982). Un análisis exhaustivo de las fuentes y estatuto de las diversas categorías gramaticales en FONTAINE, J. (1959), pp. 95- 123; FONTAINE, J. (1986); CODOÑER, C. (1998).

4 "1. Dum quaedam parva vitiorum verba non evitamus, in magnum linguae prolabimur crimen et dum facta quaedam non gravia libere ac sine metu committimus, ad potiora scelera et horrenda peccandi consuetudine labimur. 2. Sicut plerumque multiloquorum stultitia reprehenditur, ita rursum nimis tacentium vitia denotantur. Illi enim satis laxando linguam in levitatis vitio defluunt, isti nimis reticendo ab utilitate torpescunt". Isid. Sent., II, XXIX, 1-2.

Hist. R., Goiânia, v. 17, n. 2, p. 51-68, jul./dez. 2012 
5 "Latent saepe venena circumlita melle verborum, et tandiu deceptor veritatem simulat quosque fallendo decipiat”. Isid. Sent.,II, XXX, 5. En su ya clásico libro acerca de los pecados de la lengua, Casagrande y Vecchio hacen mención a la importancia del tratamiento que realiza Isidoro acerca de estos temas [Cf. CASAGRANDE, C.; VECCHIO, S. (1991), especialmente p. 23].

6 Escribe Isidoro en las Sentencias: "In scripturis sanctis, quasi in montibus excelsis, et viri perfecti habent sublimia intelligentiae, quibus gressus contemplationis quasi cervi erigant, et simplices quasi parva animalia inveniunt modicos intellectus, ad quos humiles ipsi refugiant. 4. Scriptura sacra infirmis et sensu parvulis, secundum historiam, humilis videtur in verbi; cum excellentioribus autem viris altius incedit, dum eis sua mysteria pandit, ac per hoc utrisque, manet communis, et parvulis, et perfectis”. Isid. Hisp., Sent.I, XVIII, 3-4.

7 "Officiorum plurima genera esse, sed praecipuum illud quod in sacris divinisque rebus habetur. (..) Vespertinum officium est in noctis initio, vocatum ab stella Vespere, quae surgit oriente nocte. Matutinum vero officium est in lucis initio, ab stella Lucifero appellatum, quae oritur inchoante mane. Quorum duorum temporum significatione ostenditur ut die ac nocte semper Deus laudetur" Isid. Etym. VI, 19, 1-3.

8 A propósito de esto, escribe Peter Cramer: "We can only speak of God because words are signs of things other than themselves, just as Christ as man is a sign of God. But in using language, the mind suffers constant frustration in its attempt to represent its conceptions by the signs of words". CRAMER, P. (1993), p. 104-5.

9 Dice la regla de san Benito, por ejemplo: “Caput VI. De Taciturnitate: Faciamus quod ait Propheta. Dixi: "custodiam vias meas, ut non delinquam in lingua mea: posui ori meo custodiam, obmutui et humiliatus sum et silvi a bonis. Hic ostendit Propheta si a bonis eloquiis interdum propter taciturnitatem debere tacere, quanto magis a malis-verbis propter poenam peccati debet cessari. Ergo, quamvis de bonis et sanctis et aedificationun eloquiis, perfectis discipulis propter taciturnitatis gravitatem rara loquendi concedatur licentia, quia scriptum est: in multiloquio non effugies peccatum; et alibi: Mors et vita in manibus linguae" Reg. Ben. VI, 1- 5; ed. COLOMBÁS, G. y otros (1954).

10 A manera de ejemplo, diez años después de la muerte de san Isidoro, Fructuoso de Braga instituía lo siguiente en su regla: "In cibo nullus sit strepitus, nemo comedens loquatur. Si quid deest in mensa is qui praeest signo dato vel nutibus silenter petit et indicet ministranti quod inferri vel auferri sit a mensa necesse." Fruct. Bracc., Reg III, 85- 7, ed. CAMPOS, J; ROCA MELIÁ, I. (1971). Para el tema del silencio monástico, BRUCE (2007).

11 En su regla, Isidoro también recomendaba vigilancia sobre el ejercicio de la lengua. De modo general que san Benito, el doctor de Sevilla afirmaba: “(...) a turpibus verbis vel otiosis linguam avertat, adque indesinenter cor mundum labiaque exhibeat”. Isid. Hisp., Reg. III, 56- 7, ed. CAMPOS, J; ROCA MELIÁ, I. (1971). 
12 Una visión parecida en Juan Crisóstomo [Cf. MAXWELL, J. (2006)].

13 "Dixitque Deus fiat lux et facta est lux 4 et vidit Deus lucem quod esset bona et divisit lucem ac tenebras", en Gen 1, 3-4, Biblia Sacra iuxta vulgatam versionem, ed. WEBER, R. et alii, (1983).

14 "Cuiusmodi autem lingua locutus est Deus in principio mundi, dum diceret: "Fiat lux" inveniri difficile est. Nondum enim erant linguae. Item qua lingua insonuit postea exterioribus hominum auribus, maxime ad primum hominem loquens, vel ad prophetas, vel dum corporaliter sonuit vox dicentis Dei "Tu es Filius meus dilectus", ubi a quibusdam creditur illa lingua una et sola, quae fuit antequam esset linguarum diversitas. In diversis quippe gentibus creditur quod eadem lingua illis Deus loquatur quam ipsi homines utuntur, ut ab eis intelligatur. Loquitor autem Deus hominibus non per substantiam invisibilem, sed per creaturam corporalem, per quam etiam et hominibus apparere voluit, quando locutus est”. Isid., Etym. IX, 1, 11- 12 .

15 "Omnibus animantibus Adam primum vocabula indidit, appellans unicuique nomen ex praesenti institutione iuxta condicionem naturae cui serviret. Gentes autem unicuique animalium ex propria lingua dederunt vocabula. Non autem secundum Latinam linguam atque Graecam aut quarumlibet gentium barbararum nomina illa inposuit Adam, sed illa lingua quae ante diluvium onmium una fuit, quae Hebraea nuncupatur”. Isid., Etym. XII, 1, 1-2. En su estudio, Pablo Martín Prieto recalca que esta observación de Isidoro acerca de la propiedad de los nombres de Adán no figura en el texto bíblico (cf. MARTIN PRIETO, P. (2005), pp. 5.

16 "Linguarum diversitas exorta est in aedificatione turris post diluvium. Nam priusquam superbia turris illius in diversos signorum sonos humanam divideret societatem, una omnium nationum lingua fuit, quae Hebraea vocatur; quam patriarchae et prophetae usi sunt non solum in sermonibus suis, verum etiam in litteris sacris". Isid., Etym. IX, 1, 1.

17 Comparar lo afirmado en la nota 15 con lo afirmado en la nota 16.

18 “(...) Initio autem quot gentes, tot linguae fuerunt, deinde plures gentes quam linguae; quia ex una lingua multae sunt gentes exortae”. Isid., Etym. IX, 1, 1.

19 "Linguarum diversitas exorta est in aedificatione turris post diluvium. Nam priusquam superbia turris illius in diversos signorum sonos humanam divideret societatem, una omnium nationum lingua fuit, quae Hebraea vocatur; quam patriarchae et prophetae usi sunt non solum in sermonibus suis, verum etiam in litteris sacris". Isid., Etym. IX, 1, 1.

“(...) Initio autem quot gentes, tot linguae fuerunt, deinde plures gentes quam linguae; quia ex una lingua multae sunt gentes exortae". Isid., Etym. IX, 1, 1.

"Latinas autem linguas quattuor esse quidam dixerunt, id est Priscam, Latinam, Romanam, Mixtam. Prisca est, quam vetustissimi Italiae sub Iano et Saturno 
sunt usi, incondita, ut se habent carmina Saliorum. Latina, quam sub latino et regibus Tusci et ceteri in Latio sunt locuti, ex qua fuerunt duodecim tabulae scriptae. Romana, quae post reges exactos a populo Romano coepta est, qua Naevius, Plautus, Ennius, Vergilius poetae, et ex oratoribus Gracchus et Cato et Cicero vel ceteri effuderunt. Mixta, quae post imperium latius promotum simul cum moribus et hominibus in Romanam civitatem inrumpit, integritatem verbi per soloecismos et barbarismos corrumpens." Isid., Etym. IX, 1, 6- 7. Una observación respecto de la consideración de Isidoro a la lengua de su tiempo, FONTAINE, J. (1959), pp. 127. Estudios sobre la misma, específicos en VELÁZQUEZ, I. (1989, 2003, 2004b); DÍAZ Y DÍAZ, M. (1960a, 1960b). Un panorama europeo más general del período en AUERBACH, E. (1961, 1993); BANNIARD, M. (1989, 1992, 2005); WRIGHT, R. (1996, 2004); ZAMBONI, A. (1998); CODOÑER, C. (1985), entre otros.

20 "La grammaire est "origine" des disciplines, comme l' étymologie est "origine" des vocables. (...). Elle [la grammaire] devient un système complet d' explication du monde a fortieori de la philosophie elle-même." FONTAINE, J., (1959: 53-4). Más general LAW (1995; 1997); CODOÑER (1998), MATTAHIOS, S. (2011), entre otros.

21 "The first work that deals with etymology, and uses it systematically, is Plato's Cratylus, which, by common consent, has been the traditional text on the subject ever since antiquity”. PERAKI- KYRIAKIDOU (2002), p. 478. Los críticos se posicionan de maneras muy diferentes frente a los desarrollos etimológicos propuestos por Platón en este diálogo y a las funciones que cumple: para de la Cruz Vives, el pasaje en su conjunto constituye un "delirio etimológico" (cf: DE LA CRUZ VIVES, M.); para Casadesús es un juego, una “ocurrencia”, pero que está en relación crítica con las etimologías ya propuestas por los órficos [CASADESÚS, F. (2000), p. 64 y ss.]. Modrak por su parte piensa en la misma línea lúdica (MODRAK, M. (2001), pp. 17); Van den Berg, en cambio, considera que la función de este pasaje es demostrar que los modos de nombrar tienen que ver con un modo de dividir y definir los objetos [VAN DEN BERG, R. (2008), p. XIV].

22 Así explica Marcia Colish, especialista en la tradición estoica, la articulación del método etimológico entre los estoicos y su difusión en la alta edad media: "The major contribution made by the Latin grammarians to the history of the Soic tradition is their preservation of certain features of the Stoic philosophy of language. They provide information about the Stoic conception of language as sound which naturally signifies real objects. They refer to the etymological conception of the derivation of words which stems from this theory and to the debate over analogy and anomaly in constructing the rules of grammatical declination. There is one overriding trait shared by all the grammatical writers". COLISH, M. (1990), p. 320. En referencia explícita al trabajo de Isidoro, ver FONTAINE, J. (1959), p. 41 y ss). 
23 “(...) Isidore s' est en effet appliqué á definir et illustrer quatre catégories grammaticales sous lesquelles il est possible d' envisager ses méthodes de pensée: l' analogie, l' etymologie, la glose et la "différence". (..). L'étymologie a pris le pas sur la "difference" parmi les méthodesde pensée d' Isidore, tandis que le soucide la propriété des termes reparait dans une perspective plus proprement littéraire au cours de la rhétorique". FONTAINE, J. (1959), p. 38-9.

24 Consignemos la famosa definición de Isidoro: "Etymologia est origo vocabulorum, cum vis verbi vel nominis per interpretationem colligitur.(..) Cuius cognitio saepe usum necessarium habet in interpretatione sua. Nam dum videris unde ortum est nomen, citius vim eius intellegis. Omnis enim rei inspectio etymologia cognita planior est." Isid. Etym. I, 29, 1- 2. Resulta muy indicativo los términos en que analiza esta definición a su turno Fontaine: "C'est de là que la théorie isidorienne invite cependant à partir: "L'étymologie, cést l' origine des vocables, quand on saisit le sens d' un mot ou d'un nom au moyen de son interprétation". La définition est doublement décevante: elle ignore jusqu' à l'étymologie du terme même; elle confond l' explication étymologique avec toute explication grammaticale d' un mot donné, incluant ainsi les gloses, la définition et même les "différences" sous une formule trop peu précise. Le seul mérite de ce gauchissement est qu'il approprie la définition au contenu réel des Origenes. Car l' etymologie proprement dite y cède souvent la place à de tout autres types d'explication grammaticale". FONTAINE, J. (1959), p. 41. Como podemos advertir, la definición de etimología que provee Isidoro es una guía de trabajo sobre su propia obra.

25 Fontaine hace referencia a su relación más amplia con la filosofía: "[L'étymologie] devient un système complet d' explication du monde, a fortieri de la philosophie elle-même. Et l' on verra qu' il y a dans l' ouvre d' Isidore une "grammaire de la philosophie" plutôt qu' une philosophie à propement parler". FONTAINE, J. (1959) p. 54.

26 Para un estudio de alcance general VELÁZQUEZ, I. (2003; 2004 b).

27 Un ejemplo: "Propina graecus sermo est, quae apud nos corrupte popina dicitur: est autem locus iuxta balnea publica, ubi post lavacrum a fame et siti reficiuntur. Unde et popina et propinare dicitur. Péina enim Graece famem significat, eo quod hic locus famem tollat". Isid.Hisp., Etym. XV, 2, 42.

28 "Civitas est hominum multitudo societatis vinculo adunata, dicta a civibus, id est ab ipsis incolis urbis [pro eo quod plurimorum consciscat et contineat vitas]. Nam urbs ipsa moenia sunt, civitas autem non saxa, sed habitatores vocantur". Isid. Hisp., Etym. XV, 2, 1.

29 "Urbs vocata ab orbe, quod antiquae civitates in orbe fiebant (..)". Isid. Hisp., Etym. XV, 2, 3.

30 "Suburbana sunt circumiecta civitatis aedificia, quasi sub urbe." Isid., Etym. 15, 2, 16.

31 "Cloacae dictae quod his percolantur aquae.(..)". Isid. Hisp., Etym. XV, 2, 25.

Hist. R., Goiânia, v. 17, n. 2, p. 51-68, jul./dez. 2012 
32 "Aula domus est regia, sive spatiosum habitaculum porticibus quattuor conclusum". Isid. Hisp., Etym. XV, 3, 3.

33 "Ianua a Iano quodam appellatur, cui gentiles omne introitum vel exitum sacraverunt". Isid. Hisp., Etym. XV, 7,4.

34 "Isidoro quiso también, en consecuencia, mediante su obra, volver a dar "un sentido más puro a las palabras de la tribu" (según un verso famoso de Stéphane Mallarmé: "donner un sens plus pur aux mots de la tribu") y contribuir de ese modo a la reconstrucción lingüística y, po $r$ tanto, cultural del latín, en una España que lo hablaba aún". FONTAINE, J. (2002), p. 123. Otro ejemplo en GUILLAUMIN, J. (2007).

35 "La existencia de la escritura genera unas actividades comunicativas desprendidas de la situación cara a cara. El habla se hace silencio. La lectura y la escritura convierten la expresión verbal en una actividad silenciosa y solitaria. El ritmo comunicativo se hace más lento y a distancia, con lo que las operaciones mentales que se activan son de orden distinto a las de la interacción oral. Y, por otro lado, el texto concentra en sí mismo el haz de referencias contextuales necesarias para ser interpretado adecuadamente." CALSAMIGLIA, H.; TUSÓN, A. (1999), p. 81.

36 "El hecho de que tantas y tantas definiciones se hayan quedado vacías no ha restado interés a la posteridad ante la obra más difundida de Isidoro, porque lo más importante en ella era, de un lado el sistema, de otro las autoridades aducidas, la comodidad de disponer de un repertorio de erudición debidamente ordenado y clasificado, y además el sentido precioso y aun único de la cultura clásica que hizo de su libro la introducción más completa a toda la ciencia de la época. " DÍAZ Y DÍAZ, M. (1976), p. 36.

37 "[Isidoro] busca llegar a la corrección [lingüística] y transmitirla a sus lectores para que aprendan a hablar y a escribir correctamente y a utilizar la lengua con propiedad y riqueza." VELÁZQUEZ, I. (2004 a). También RODRÍGUEZ PANTOJA, M. (2002), pp. 95 y ss.

38 Un ejemplo: "Aram vocatam dixerunt quod ibi incensae victimae ardeant. Alii aras dicunt a precationibus, id est quas Graeci arás, dicunt; unde contra imprecario katára dictur. Alii volunt ab altitudine aras, sed male." Isid., Etym. 15, 4, 13.

39 A propósito de esto, anota Codoñer: "El criterio de Isidoro se erige en único criterio, si matizaciones ni resquicios para la controversia. $\mathrm{Y}$ ese criterio, en todos los casos, es un criterio que parte de una idea dominante: facilitar el conocimiento. Cassiodoro escribe para sus monjes, en un monasterio cuya biblioteca, si atendemos a lo que de sus Instituciones se desprende, es una biblioteca bien dotada. Isidoro escribe para una amplia comunidad dispersa, cuya capacidad de lectura incluso está muy mermada, y cuya posibilidad de acceder al libro es más que dudosa”. CODOÑER MERINO, C. (2002), p. 128. Un estudio de la obra en CODOÑER, C. (2008). 
40 "No hay, por lo tanto, dificultad en afirmar que Isidoro es el puente que une la Antigüedad con la Edad Media, pero en el sentido de que su vuelta hacia la antigüedad se hace en función exclusiva de la erudición, como instrumento de trabajo para la formación más completa del hombre eclesiástico.” DÍAZ Y DÍAZ, M. (1976: 37).

41 Henri de Lubac explica de este modo la doble dimensión del trabajo sobre el signo: "Aussi bien que saint Augustin lui même, aussi bien que son maître plus proche, saint Isidore de Séville, aussi bien que son compatriote Grégoire d'Elvire, [Ildephose de Toléde] sait que pour demeurer dans ce corps du Christ qu' est la sainte Église, on doit participer en toute vérité, par le sacrement, à un premier corps du Christ. Mis, pas plus qu' eux, il ne s'arrète à la présence pour s' en former un concept indépendant. "Il découvre l' union réelle avec le Chist, non pas tant à travers la présence réelle, mais à travers le signe, et cette union n'est pas tant l' union individuelle que celle des individus entre eux dans le Chist." DE LUBAC (1949: 24). Para un estudio de las funciones de los signos, símbolos e imágenes en las iglesias orientales ver MURRAY (1975).

42 A propósito de esto, Fontaine escribe: "La plume est d' abord pour Isidore un instrument d' action sur ses disciples, sur les clercs et les moines dont il assume directement ou indirectemente la charge, sur l' Eglise d' Espagne, et même sur son “maître et fils Sisebut", le prince régnant à Tolede". FONTAINE, (1960: 89- 90).

43 La bibliografía sobre reforma gregoriana es inmensa. En español, la compilación de Estella resulta fundamental (AAVV: 2006). Un panorama general actualizado en SÁNCHEZ HERRERO (2005).

44 Ver GARCÍA GALLO (1969).

45 "Despite their shared appeal to the authority of literature culture, however, [Sisebute's and Isidore's] views and policies differed significantly. The king advocated royally legislated forced conversion as the means to establish and maintain Christian consensus, while Isidore's vision of social order was centered on clerical education and discipline". STOCKING (2003:120).

46 De acuerdo a la cronología que señala Fontaine, Isidoro probablemente ya haya publicado para 619 las Allegoriae (612- 5); la primera versión de su Chronicon (615); De Differentiis (598- 615); los Synonima (610- 615) De fide contra Iudaeos (614-5); De haeresibus (612- 5); Liber numerorum (612-5); De natura rerum (613); De origine gothorum (619); De ortu et obitu Patrum (598- 615); la Regula Monachorum (615-8), y esbozado incluso algunas partes de sus Etymologiae (612- 625?). Para el resto de sus obras, consultar FONTAINE, J., (2002: 311 y ss.).

47 "Prona est omnis aetas ab adulescentia in malum. Nihil enim incertius quam vita adolescentium. Ob hoc constituendum oportuit ut si qui in clero puberes aut adulescentes existunt, omnes in uno conclavi atrii conmorentur, ut lubricae aetatis annos non in luxuria sed in disciplinis ecclesiasticis agant deputati probatissimo 
seniori quem et magistrum doctrinae et testem vitae habeant. Quod si aliqui ex his pupilli existunt, sacerdotali tutela foveantur ut et vita eorum a criminibus intacta sit et res ab iniuria improborum. Qui autem his preaeceptis resultaverint, monasteriis deputentur, ut vagantes animi et superbi severiori regula distrigantur". Tol. IV, XXIV, ed. MARTÍNEZ DIEZ, G. (1992).

48 "Ignorantia mater cunctorum errorum maxime in sacerdotibus Dei vitanda est, qui docendi officium in populis susceperunt. Sacerdotes enim legere sancta scriptura admonet, Paulo apostolo dicente ad Timotheum: "Intende lectioni, exhortationi, doctrinae, semper permane in his". Sciant igitur sacerdotes scripturas sanctas et canones ut omne opus eorum in praedicatione et doctrina consistant atque aedificent cunctos tam fidei scientia quam operum disciplina". Tol. IV, XXV.

49 "Apocalipsin librum multorum conciliorum auctoritas et synodica sanctorum praesulum Romanorum decreta Ioannis evangelistae esse praescribunt et inter divinos libros recipiendum constituerunt. Et quia plurimi sunt qui eius auctoritatem non recipiunt atque in ecclesiam Dei praedicare contemnunt, si quis eum deinceps aut non receperit aut a pascha usque ad pentecosten missarum tempore in ecclesia non praedicaverit, excomunicationis sententiam habebit". Tol. IV, XVII.

50 A modo ilustrativo: "Non aliter placuit ut quemadmodum antistites ita presbyteresatque Levitae quos forte infirmitas aut aetatis gravitas in conclavi episcopi manere non sinit, ut et idem in cellulis suis testes vitae habeant vitamque suam sicut nomine ita et meritis teneant". Tol. IV, XXIII.

51 Un ejemplo: "Post rectae fidei confessionem quae in sancta Dei ecclesia praedicatur, placuit ut omnes sacerdotes qui catholicae fidei unitate conplectimur, nihil ultra diversum aut dissonum in ecclesiasticis sacramentis agamus, ne qualibet nostra diversitas apud ignotos seu carnales schismatis errorem videatur otendere, et multis existat in scandalum varietas ecclesiarum. (...)". Tol. IV, 2.

52 Para esto, ver VELÁZQUEZ (1999).

\section{Biblografía CITADA}

AAVv., La reforma gregoriana y su proyección en la cristiandad occidental. Siglos XI- XII. Pamplona, 2006.

Auerbach, E. Introduction to romance languages and literature. Nueva York, 1961.

Auerbach, E. Literacy, language and its public in late latin antiquity and in the Middle Ages. Princeton, 1993.

Banniard, M. Viva Voce. Communication écrite et communication orale du Ive au IX siècle en Occident Latin. Paris: Institut d' études Agustiniennes, 1992.

Banniard, M. Genèse culturelle de l' Europe (Ve- VIII siècle). París, 1989. 
BAnniard, M. Niveaux de langue et communication latinophone. Comunicare e significare nell' alto medioevo. Spoleto, 15- 20 aprile 2004. Spoleto, 2005.

BRUCE, S. Silence and sign language in Medieval Monasticism. The Cluniac Tradition c. 900- 1200. Cambridge, 2007.

Calsamiglia Blancafort, H.; Tusón Valls, A. Las cosas del decir. Manual de análisis del discurso. Barcelona: Ariel,CC 1999.

Casadesús Bordoy, F. Nueva interpretación del Crátilo platónico a partir de las aportaciones del papiro de Derveni. Emérita, LXVIII, 1, 2000.

Casagrande, C.; Vecchio, S. Les péchés de la langue. Discipline et éthique de la parole dans la culture médiévale. París, 1991.

Codoñer, C. Latín cristiano, ¿lengua de grupo? Nova Tellus 3, 1985.

CoDoÑER, C. La gramática y las artes liberales. Morfologie sociali e culturali in Europa fra tarda antichitá e Alto Medioevo. XLV settimana di Studio del Centro Italiano di Studi sull' alto medioevo, Spoleto, 1998.

Codoñer, C. El carácter no doctrinal de Isidoro de Sevilla. En: GonzÁlez Fernández, J. (coord.) San Isidoro, doctor Hispaniae. Sevilla: Fundación El MonteUniversidad de Sevilla, 2002.

Codoñer, C. Problemas de transmisión en la primera parte de las Etimologías: algunas reflexiones. En: Andrés SAnz, M.; Elfassi, J.; Martín, J., L'édition critique des ouvres d'Isidore de Séville. Les recensions multiples. Actes du colloque organisé à la Casa de Velázquez et à l' Université Rey Juan Carlos de Madrid (14- 15 janvier 2002). Paris: Institut d' Études Augustiniennes, 2008.

Colish, M. The Stoic tradition from Antiquity to the Early Middle Ages, T. I, Leiden, 1990.

Cramer, P. Baptism and change in the Early Middle Ages. C. 200- 1150. Cambridge, 1993.

De Lubac, H. Corpus mysticum. L'eucharistie et l'église au Moyen Age. París, 1949.

DíAz Y DíAz, M. El latín de la península ibérica. Dialectismos. Enciclopedia lingüística hispánica, TI, Madrid, 1960.

DíAz Y DíAz, M. El latín de la península ibérica. Rasgos lingüísticos. Enciclopedia lingüística hispánica, TI, Madrid, 1960.

DíAz Y DíAz, M De Isidoro al siglo XI. Estudios sobre la vida literaria peninsular. Barcelona, 1976.

Fontaine, J. Isidore de Séville et la culture classique dans l' Espagne wisigothique. TI, París, 1959.

Fontaine, J. Théorie et pratique du style chez Isidore de Séville. Vigiliae Christianae 14,2 , jun 1960 . 
Fontaine, J. Grammaire sacrée et grammaire profane: Isidore de Séville devant l' exégese biblique. Antigüedad y cristianismo III, 1986.

Fontaine, J. Isidoro de Sevilla. Génesis y originalidad de la cultura hispánica en tiempos de los visigodos. Madrid, 2002.

GARCíA GALLO, A. San Isidoro jurista. Isidoriana. Estudios sobre san Isidoro de Sevilla en el XIV aniversario de su nacimiento. León, 1969.

J. Guillaumin, "Les marqueurs de limits dans les Étymologies d' Isidore de Séville (XV, 14)" Gerion 25, 2007.

LAw, V. Wisdom. Authority and Grammar in the seventh century. Decoding Virgilius Maro Grammaticus. Cambridge: Cambridge University Press, 1995.

LAw, V. Grammar and grammarians in the Early Middle Ages. London- New York: Longman, 1997.

Martin Prieto, P. Isidoro de Sevilla frente a los límites del conocimiento: etimología, astrología, magia. Temas Medievales. vol.13, ene./dic. 2005.

Matthaios, S.; Montenari, F.; Rengakos, A. (eds.), Ancient scholarship and Grammar. Archetypes, concepts and concepts. De Gruyter, Berlin- New York, 2011.

MAXwell, J. Christianization and communication in Late Antiquity. John Chrisostom and his congregation in Antioch. Cambridge, 2006.

Modrak, D. Aristotle's theory of language and meaning. Cambridge: Cambridge University Press, 2001.

Murray, R. Symbols of chruch and kingdom. A study in Early syriac tradition. Cambridge, 1975.

Peraki Kyriakidou, H. Aspects of ancient etymologizing. The classical Quaterly. New Series 52, n. 2, 2002.

Rodríguez Pantoja, M. La obra de san Isidoro de Sevilla, las Etimologías. En: J. González Fernández, J. (coord.), San Isidoro, doctor Hispaniae. Sevilla: Fundación El Monte- Universidad de Sevilla, 2002.

Sánchez Herrero, J. Historia de la Iglesia. T. II: La edad Media. Madrid, 2005.

R. Stocking, R. Bishops, Councils, and Consensus in the Visigothic Kingdom, 589633. Michigan, 2003.

Velázquez Soriano, I. Las pizarras visigodas. En: Antigüedad y Cristianismo. Monografías históricas sobre la Antigüedad tardía VI, 1989.

VelázQuez Soriano, I. Impronta religiosa en el desarrollo jurídico de la España visigoda. En: http://www.ucm.es/BUCM/revistas/ccr/11354712/articulos/ ILUR9999440097A. PDF (1999). 
Velázquez Soriano, I. Latine dicitur, vulgo vocant. Aspectos de la lengua escrita y hablada en las obras gramaticales de Isidoro de Sevilla. Logroño: Fundación san Millán de la Cogolla, 2003.

Velázquez Soriano, I. De constructione. Lengua y literatura técnica en las etimologías de Isidoro de Sevilla (a propósito de un libro reciente de Mortero Castilla) En: Antigüedad y cristianismo, XXI, 2004 a.

Velázquez Soriano, I. Formación de palabras en las Etimologías de Isidoro de Sevilla: un reflejo de la lengua viva de su época. Aemilianense 1, 2004b.

Van Den Berg, R. Proclus commentary on the Cratylus in context. Ancient Theories on language and naming, Brill, Leiden- Boston, 2008.

Wright, R. Latin and the Romance languages in the early Middle ages. Pennsylvania, 1996.

Wright, R. Latinistas tardíos y romanistas tempranos. Signo. Revista de Historia de la cultura escrita, 14, 2004.

ZAмвоNI, A. Dal latino tardoantico agli albori romanzi: dinamiche linguistiche della transizione. Morfologie sociali e culturali in Europa fra tarda antichitá e Altomedioevo. 3-9 aprile 1997, T. II: Settimane di Studio del Centro Italiano di Studi sull' alto medioevo, Spoleto, 1998. 